\title{
Students' Perceptions of Equal Opportunities for Higher Education
} Persepsi Mahasiswa Terhadap Persamaan
Kesempatan Memperoleh Pendidikan Tinggi

\author{
Noora Fithriana*, Firman Firdausi \\ Universitas Tribhuwana Tunggadewi Malang, Indonesia
}

The research's aim was to measure perception of students to equality of opportunity getting higher education at Tribhuwana Tunggadewi University. In order to meet the aim and collect the primary data, a questionnaire survey was held to 326 Tribhuwana Tunggadewi active students of the year 2019 by simple random sampling. Data was validated by constructed validity and Alpha Cronbach. It was analy ed by quantitative technique by using Microsoft Excel and IBM SPSS 22. The research's results measured the prospects that most students perceived "yes" the various admission pathways $(M=6)$; the adequate admission phases $(M=6)$; the understandable information and requirements $(M=$ 6); the campus promotion got to school $(M=5)$; most students perceived an admission opportunity to all groups ( $\mathrm{M}=6)$; and most students perceived "no" ethnic discrimination when registered $(M=4)$. Of the means equality, most students perceived "yes" the admission test admitted to all registrants $(M=6)$; the scores of general test informed to the registrants $(M=6)$; the registration rules applied for all registrants $(M=6)$; the schedule of general test informed before $(M=6)$; the applicants' achievements, interests, and talents considered in the admission $(M=6)$; and the granted applicants of the general test

OPEN ACCESS ISSN 25482254 (online) ISSN 20893833 (print)

Edited by: Muhlasin Amrullah

Reviewed by:

Emy Pratiwi

*Correspondence: Noora Fithriana noora.fithriana@unitriac.id

Received: 3 Agustus 2020 Accepted: 10 Agustus 2020 Published: 17 Agustus 2020

Citation:

Fithriana N and Firdausi F (2020) Students' Perceptions of Equal Opportunities for Higher Education. PEDAGOGIA: Jurnal Pendidikan. accepted $(M=6)$. Those results had score 6 in the undergraduate-students' perception, that it was true significantly by the mean of perception equalled.

\section{Keywords: Equality, Higher Education, Opportunity, Student Perception}

Tujuan penelitian mengukur persepsi mahasiswa terhadap persamaan kesempatan memperoleh pendidikan tinggi pada Universitas Tribhuwana Tunggadewi. Untuk mencapai tujuan dan mengumpulkan data primer, survei dengan kuesioner telah dilakukan kepada 326 mahasiswa aktif program sarjana angkatan 2019 Universitas Tribhuwana Tunggadewi secara acak sederhana. Keabsahan data dengan validitas konstruk dan Cronbach Alpha. Data dianalisis dengan teknik kuantitatif dengan menggunakan Ms Excel dan IBM SPSS 22. Hasil penelitian mengukur bahwa dari segi peluang, sebagian besar mahasiswa mempersepsikan "ya" jalur pendaftaran beragam (rerata 6), gelombang pendaftaran mencukupi (rerata 6), informasi dan persyaratan pendaftaran jelas (rerata 6), promosi kampus sampai ke sekolah (rerata 5), sebagian besar mahasiswa mempersepsikan kesempatan mendaftar untuk semua golongan (rerata 6), serta sebagian besar mahasiswa mempersepsikan "tidak" diskriminasi suku ketika mendaftar (rerata 4). Dari kesempatan aturan, sebagian besar mahasiswa mempersepsikan "ya" 
tes masuk berlaku untuk semua pendaftar (rerata 6), skor hasil tes umum diinformasikan kepada pendaftar (rerata 6), aturan pendaftaran adil untuk semua pendaftar (rerata 6), jadwal tes umum diinformasikan sebelumnya (rerata 6), prestasi, minat dan bakat dipertimbangkan saat pendaftaran (rerata 6) dan pendaftar yang dinyatakan lulus tes umum diterima (rerata 6). Didapatkan ukuran bahwa benar secara signifikan rerata persepsi sama dengan 6 dalam persepsi mahasiswa S1.

Keywords: Equality, Higher Education, Opportunity, Student Perception

\section{PENDAHULUAN}

Persamaan kesempatan dalam pendidikan adalah suatu prinsip keadilan distributif yang diterima secara luas di masyarakat liberal Barat dan negara-negara kesejahteraan (welfare states). Terkadang, persamaan kesempatan untuk pendidikan dikatakan sebagai prinsip-prinsip hak untuk disediakan sumber-sumber pendidikan yang sama untuk seluruh pemuda atau dengan penyediaan persamaan di dalam pencapaian-pencapaian pendidikan bagi semua individu dengan dihilangkannya diskriminasi terbuka pada ras atau gender. Di dalam pemikiran ini, terdapat ketidaksepakatan yang luas tentang apa kebutuhan persamaan kesempatan bidang pendidikan itu. Bagi beberapa pihak, masing-masing anak diizinkan secara legal untuk pergi ke sekolah sedangkan bagi yang lainnya adalah masing-masing anak mendapatkan sumberdaya pendidikan yang sama. Guna mengatasi perdebatan ini, Lazenby (2016) membangun sebuah kerangka konsep persamaan kesempatan yang penting tapi ditelantarkan dan mengaplikasikannya untuk menguji konsepsi khusus tentang persamaan kesempatan di bidang pendidikan.

Mengenai persamaan kesempatan, Salehi-Isfahani, Salehi-Isfahani et al. (2014) melakukan investigasi empiris dari ketidaksamaan kesempatan pendidikan di Timur Tengah dan Afrika Utara. Di dalam penelitian itu, diujikan sejauh mana sistem pendidikan telah memenuhi tujuan-tujuan distribusionalnya dalam hal pemenuhan bidang pendidikan. WEST and NIKOLAI (2013) memfokuskan penelitiannya pada fitur-fitur pendidikan yang diasosiasikan dengan ketidaksamaan dari kesempatan bidang pendidikan yang hasilnya mampu mengidentifikasikan empat klaster negara. Jika penelitian-penelitian sebelumnya berangkat dari ketidaksamaan untuk dapat menjelaskan perihal persamaan kesempatan, Jia and Ericson (2017) berfokus pada prinsip operatif tentang persamaan kesempatan pendidikan di China pada akses pendidikan tinggi. Temuan-temuan kuantitatif menjawab "bagaimana" dan temuan-temuan kualitatif menjawab "mengapa" Status Sosial Ekonomi (SES) keluarga, lokasi rumah, pendidikan menengah atas yang didapat, etnis dan gender mempengaruhi kesempatan-kesempatan pendidikan mahasiswa ke perguruan tinggi.

Pendidikan tinggi menjadi fokus perhatian penelitian ini. ejak diselenggarakannya pendidikan tinggi sesudah kemerdekaan di Indonesia, soal kesempatan memang masih menjadi salah satu permasalahan yang mendasar. Akses pendidikan tinggi ditunjukkan dengan Angka Partisipasi Kasar (APK) pendidikan tinggi Indonesia tahun 2010 yang masih rendah yakni 21,49 $\%$ untuk usia 19-23 tahun, padahal APK perguruan tinggi di negara lain mencapai lebih dari $40 \%$ (Alawiyah, 2012). Dalam kurun waktu lebih dari lima tahun, total jumlah mahasiswa di Indonesia mencapai 7,5 juta orang terbilang masih kecil dibandingkan dengan populasi usia pendidikan (Nursalikah, 2018). alah satu penyebab kurangnya minat terhadap pendidikan perguruan tinggi pada pemuda dan pemudi dikarenakan oleh himpitan ekonomi Gustian (2016).

Sebagai kampus swasta nasional yang turut melaksanakan kebijakan Pemerintah Indonesia dalam memperluas kesempatan pendidikan tinggi, Universitas Tribhuwana Tunggadewi (UNITRI) Malang berani mengambil bagian dalam kepedulian terhadap mahasiswa yang memiliki keinginan kuliah namun memiliki keterbatasan dalam hal pembiayaan pendidikan dengan cara memberikan beasiswa Wea and Adiwidjaja (2018). Universitas Tribhuwana Tunggadewi (UNITRI) Malang memberikan beasiswa pendidikan tinggi $100 \%$ dengan menyertakan Surat Keterangan Tidak Mampu (SKTM) dari kepala desa/kelurahan setempat (IMC, 2017). Sebagian besarnya berasal dari wilayah Indonesia bagian Timur, dengan mata pencaharian orang tua adalah petani Mitasari and Istikomayanti (2017). Tidak hanya dari Indonesia Timur, dalam usaha memperluas kesempatan pendidikan tinggi, Universitas Tribhuwana Tunggadewi 
(UNITRI) juga menjalin kerjasama dengan Pemerintah Daerah Sanggau yang mengirimkan masyarakatnya untuk berkuliah karena orang-orang dusun dan desa masih banyak yang belum sarjana Alfian and Diskominfo (2019) .

Penelitian yang dilakukan ini bertujuan untuk mengukur persepsi mahasiswa terhadap persamaan kesempatan memperoleh pendidikan tinggi pada Universitas Tribhuwana Tunggadewi (UNITRI). Penelitian berangkat dari dugaan bahwa rerata persepsi sama dengan 6 dalam persepsi populasi mahasiswa $\mathrm{S} 1\left(\mathrm{H}_{0}: \mu=6\right)$. Dengan dugaan ini dilakukan pengujian apakah hipotesis null $\left(\mathrm{H}_{0}\right)$ adalah benar sama dengan diantara persepsi mahasiswa S1. Di dalam konteks persamaan kesempatan, H. George Frederickson membagi persamaan-persamaan kesempatan (equalities of opportunity) ke dalam kesempatan peluang (prospect) dan aturan (means). Jika konteks ini dibawa ke sektor pendidikan tinggi, maka di dalam kesempatan peluang seluruh calon mahasiswa mendapatkan kesempatan yang sama untuk masuk universitas. Sedangkan di dalam kesempatan aturan, diantara calon-calon mahasiswa akan mendapatkan kesempatan yang sama untuk masuk universitas jika memiliki prestasi atau kualifikasi yang sama. Variabel bebas persamaan kesempatan (X) di dalam penelitian ini telah dijabarkan ke dalam 12 item. Kedua belas item itu berhubungan dengan kesempatan peluang untuk mendaftar dan aturan untuk bisa masuk ke Universitas Tribhuwana Tunggadewi (UNITRI), mulai dari peluang melalui jalur pendaftaran hingga aturan diterima (lulus) tes umum.

\section{METODE}

Metode kuantitatif deskriptif digunakan di dalam penelitian ini untuk mendeskripsikan ukuran persepsi mahasiswa terhadap persamaan kesempatan memperoleh pendidikan tinggi. Penelitian ini berlokasi di Universitas Tribhuwana Tunggadewi (UNITRI), Jalan Telaga Warna, Tlogomas, Kota Malang karena kampus ini merupakan miniatur Indonesia. Subjek dari penelitian ini adalah responden. Responden dimaksudkan sebagai pihak yang memberikan keterangan diri dan persepsinya mengenai persamaan kesempatan memperoleh pendidikan tinggi. Responden penelitian ini adalah mahasiswa aktif angkatan tahun 2019 Universitas Tribhuwana Tunggadewi (UNITRI) karena persepsinya masih fresh. Jumlah mahasiswa Universitas Tribhuwana Tunggadewi (UNITRI) angkatan tahun 2019 yang melakukan her-registrasi (aktif) berdasarkan data dari UPT Pemaba adalah 1.757 orang (Data Sekunder, 2019). Dari jumlah populasi tersebut, diambil $5 \%$ atau 0,05 tingkat kesalahan sehingga didapatkan ukuran sampel sebesar 326 dengan menggunakan rumus Slovin. Dengan begitu, jumlah responden di dalam penelitian ini adalah 326 mahasiswa aktif angkatan 2019.

Teknik pengambilan data primer penelitian ini telah dilakukan dengan kuesioner pada Februari-Maret 2020. Pada awal kegiatan, kuesioner diujicobakan dengan mendistribusikannya kepada 30 mahasiswa aktif program sarjana Universitas Tribhuwana Tunggadewi (UNITRI). Sesudah dipertimbangkan bahwa kuesioner telah layak dan teruji, maka dilakukan survei dengan kuesioner untuk mendapatkan respon dari 326 mahasiswa aktif program sarjana Universitas Tribhuwana Tunggadewi (UNITRI) angkatan 2019. Kuesioner penelitian ini merupakan daftar pertanyaan tertutup dengan alternatif-alternatif jawaban yang telah disiapkan untuk mendapatkan respon dari para responden, yang dibuat anonim. Meskipun demikian, para responden tetap diminta untuk mengisi bagian demografi responden dan memberikan persepsinya terhadap variabel persamaan kesempatan. Untuk mengukur persepsi mahasiswa, kedua belas item variabel bebas persamaan kesempatan (X) diberikan skala Likert yang bernilai 1-7 dimana 1 berarti tidak, tujuh berarti ya, sedangkan nilai di tengah-tengah berarti netral, ragu-ragu, atau bisa juga tidak tahu.

Untuk melihat kesahihan, serta kehandalan dari kuesioner penelitian dilakukan uji validitas-reliabilitas. Instrumen divalidasi dengan memperhatikan validitas internal dan eksternal. Kuesioner sebagai instrumen dalam penelitian ini bisa dikatakan telah memenuhi validitas konstruk karena dapat mengukur persamaan kesempatan (variabel X) berdasarkan teori persamaan kesempatan (equality of opportunity) dari H. George Frederickson. Sedangkan untuk menguji validitas konstruk, bantuan IBM SPSS 22 dipergunakan. Semua item pernyataan pada variabel persamaan kesempatan adalah valid atau sah karena didapat $r$ hitung $>r$ tabel 0,306. 
Dilakukan juga uji reliabilitas menggunakan IBM SPSS 22. Dapat dikatakan bahwa variabel persamaan kesempatan adalah reliabel dengan skor Cronbach Alpha 0,780. Karena data penelitian ini valid dan reliabel, maka dilanjutkan dengan proses analisis data. Di dalam menganalisis data digambarkan frekuensi dari demografi responden dan variabel persamaan kesempatan, serta mean, median dan modus dari variabel persamaan kesempatan dengan IBM SPSS 22. Selanjutnya, dilakukan pengujian hipotesis dengan $z$-test dengan level signifikansi $5 \%$ yang dibantu oleh Ms Excel dan IBM SPSS 22 agar dapat membuktikan kebenaran hipotesis.

\section{HASIL DAN PEMBAHASAN}

Persepsi mahasiswa terhadap variabel persamaan kesempatan memperoleh pendidikan tinggi di Universitas Tribhuwana Tunggadewi (UNITRI) telah diukur dengan skala Likert 7 di setiap itemnya. Dari hasil pengukuran item dengan skala Likert, sebagian besar mahasiswa mempersepsikan "ya" jalur pendaftaran pada Universitas Tribhuwana Tunggadewi (UNITRI) beragam. Sebagian besar mahasiswa mempersepsikan "ya" gelombang pendaftaran pada Universitas Tribhuwana Tunggadewi (UNITRI) mencukupi. Sebagian besar mahasiswa mempersepsikan "ya" informasi dan persyaratan pendaftaran pada Universitas Tribhuwana Tunggadewi (UNITRI) jelas. Sebagian besar mahasiswa mempersepsikan "ya" promosi kampus Universitas Tribhuwana Tunggadewi (UNITRI) sampai ke sekolah. Sebagian besar mahasiswa mempersepsikan bahwa kesempatan mendaftar ke Universitas Tribhuwana Tunggadewi (UNITRI) untuk semua golongan. Sebagian besar mahasiswa mempersepsikan "tidak" diskriminasi suku ketika mendaftar ke Universitas Tribhuwana Tunggadewi (UNITRI). Sebagian besar mahasiswa mempersepsikan "ya" tes masuk Universitas Tribhuwana Tunggadewi (UNITRI) berlaku untuk semua pendaftar. Sebagian besar mahasiswa mempersepsikan "ya" skor hasil tes umum Universitas Tribhuwana Tunggadewi (UNITRI) diinformasikan kepada pendaftar. Sebagian besar mahasiswa mempersepsikan "ya" aturan pendaftaran pada Universitas Tribhuwana Tunggadewi (UNITRI) adil untuk semua pendaftar. Sebagian besar mahasiswa mempersepsikan "ya" jadwal tes umum pada Universitas Tribhuwana Tunggadewi (UNITRI) diinformasikan sebelumnya. Sebagian besar mahasiswa mempersepsikan "ya" prestasi, minat dan bakat dipertimbangkan saat pendaftaran pada Universitas Tribhuwana Tunggadewi (UNITRI). Sebagian besar mahasiswa mempersepsikan "ya" pendaftar yang dinyatakan lulus tes umum diterima pada Universitas Tribhuwana Tunggadewi (UNITRI).

Rekapitulasi jawaban responden terhadap variabel persamaan kesempatan memperoleh pendidikan tinggi pada Universitas Tribhuwana Tunggadewi (UNITRI) dapat dilihat dalamTabel 1 .

[Table 1 about here.]

Dengan rekapitulasi ini, dapat disimpulkan bahwa item kesepuluh dari variabel persamaan kesempatan $(\mathrm{X})$, yaitu jadwal tes umum diinformasikan sebelumnya mempunyai rerata yang paling tinggi diantara item-item lainnya, yaitu 6,4755. Jika disusun mulai dari rerata terbesar ke rerata terkecil, maka item-item pada variabel persamaan kesempatan menjadi: (1) Jadwal tes umum diinformasikan sebelumnya $(M=6)$; (2) Pendaftar yang dinyatakan lulus tes umum diterima $(M=6)$; (3) Jalur pendaftaran UNITRI beragam $(M=6)$; (4) Aturan pendaftaran adil untuk semua pendaftar $(M=6)$; (5) Gelombang pendaftaran UNITRI mencukupi $(M=6)$; (6) Kesempatan mendaftar ke UNITRI untuk semua golongan $(\mathrm{M}=6)$; (7) Tes masuk UNITRI berlaku untuk semua pendaftar $(M=6)$; (8) Skor hasil tes umum diinformasikan kepada pendaftar $(M=6)$; (9) Informasi dan persyaratan pendaftaran UNITRI jelas $(M=6)$; (10) Prestasi, minat dan bakat dipertimbangkan saat pendaftaran $(M=6)$; (11) Promosi kampus UNITRI sampai ke sekolah $(\mathrm{M}=5)$; dan (12) Diskriminasi suku ketika mendaftar ke UNITRI $(\mathrm{M}=4)$.

Untuk membuktikan signifikansi persepsi mahasiswa terhadap persamaan kesempatan memperoleh pendidikan tinggi di Universitas Tribhuwana Tunggadewi (UNITRI), telah dilakukan pengujian hipotesis dengan $z$-test dengan kombinasi bantuan Ms Excel dan IBM SPSS 22. Hasilnya dapat dilihat dalam Tabel 2 . 
[Table 2 about here.]

Uji z menghasilkan nilai p yakni probabilitas dari z statistik. Nilai $p$ telah diperoleh dari perhitungan jumlah sampel $(\mathrm{n}=326)$, rerata sampel (lihat Tabel 1), rerata populasi $(\mu=6)$ dan standar deviasi dari populasi $(\sigma=2)$ dengan IBM SPSS 22. Di dalam penelitian ini, pengujian hipotesis telah dilakukan dengan one-tailed $z$-test sehingga masing-masing nilai $\mathrm{p}$ dikalikan dengan 1. $\mathrm{p}_{1}=(1,00) \times 1=1,00 \cdot \mathrm{p}_{2}=(1,00) \times 1=1,00 \cdot \mathrm{p}_{3}=(1,00) \times 1=1,00 \cdot \mathrm{p}_{4}=(0,00) \times 1$ $=0,00 \cdot \mathrm{p}_{5}=(1,00) \times 1=1,00 \cdot \mathrm{p}_{6}=(0,00) \times 1=0,00 \cdot \mathrm{p}_{7}=(1,00) \times 1=1,00 \cdot \mathrm{p}_{8}=(1,00) \times 1=$ $1,00 \cdot \mathrm{p}_{9}=(1,00) \times 1=1,00 \cdot \mathrm{p}_{10}=(1,00) \times 1=1,00 \cdot \mathrm{p}_{11}=(1,00) \times 1=1,00 \cdot \mathrm{p}_{12}=(1,00) \times 1=$ 1,00. Dari hasil ini, ditemukan bahwa jika $\mathrm{H}_{0}$ adalah benar dan signifikansi probabilitas rerata sampel telah teruji dari populasinya dengan level signifikansi $5 \%(\alpha=0,05)$. Hitungan dengan Ms Excel menghasilkan semua nilai $\mathrm{p}>0,05$ karenanya diputuskan $\mathrm{H}_{0}$ diterima $\left(\mathrm{H}_{0}: \mu=\right.$ 6). Keputusan ini berarti bahwa benar rerata persepsi sama dengan 6 dalam persepsi populasi mahasiswa S1. Jadi, rerata persepsi terhadap persamaan kesempatan memperoleh pendidikan tinggi diantara mahasiswa program S1 Universitas Tribhuwana Tunggadewi (UNITRI) adalah sama dengan 6 secara signifikan.

Berdasarkan hasil penelitian ini, sebagian besar mahasiswa S1 angkatan 2019 Universitas Tribhuwana Tunggadewi (UNITRI) mempersepsikan "ya" dari segi aturan, namun tidak semua dari kesempatan peluang. Pada Universitas Tribhuwana Tunggadewi (UNITRI), aturan pendaftaran telah dipersepsikan adil untuk semua pendaftar. Bahkan, dipertimbangkannya prestasi, minat dan bakat dan/atau tes tulis umum berlaku untuk semua pendaftar, dimana materi tesnya terdiri dari tes potensi umum Unitri (2019a). Selain itu, jadwal tes tulis diinformasikan sebelumnya dalam brosur sedangkan skor dan hasil seleksi penerimaan mahasiswa baru juga diinformasikan kepada pendaftar melalui media resmi, laman dan situs kampus oleh UPT Pemaba (d.a. UPMB). Sebelumnya diinformasikan oleh UPT Pemaba UNITRI bahwa 620 peserta ditargetkan akan diterima dalam penerimaan gelombang kedua, sementara untuk rencana ke depan, akan digelar tes penerimaan gelombang ketiga pada 14 Agustus 2019 Unitri (2019a). Kesempatan aturan masuk Universitas Tribhuwana Tunggadewi (UNITRI) tidak seketat seperti persaingan penerimaan mahasiswa pada perguruan-perguruan tinggi negeri atau swasta lainnya, seperti lewat jalur SPMB dan PMDK. Didukung oleh Matondang (2015), ermasalahan sistem Seleksi Penerimaan Mahasiswa Baru (SPMB) akhir-akhir ini banyak diperdebatkan lagi akurasi dan keadilannya (equity). Sedangkan Penelusuran Minat dan Kemampuan (PMDK), seperti pada Universitas Jenderal Achmad Yani (UNJANI), masih akan menyeleksi sesuai kuota 10 $\%$ dari total mahasiswa baru yang diterima untuk setiap program studi Novianti and Tripambudi (2015). Sehingga, dapat dipersepsikan bahwa kesempatan dari segi aturan masuk Universitas Tribhuwana Tunggadewi (UNITRI) adalah sama, adil untuk semua calon mahasiswa yang mendaftar.

Menurut Turner et al. (2012), kriteria masuk universitas bisa menjadi suatu topik yang diperselisihkan, terutama dalam kepatuhan tentang keadilan sehingga perbaikan-perbaikan dari kriteria itu dapat memiliki dampak positif terhadap pihak-pihak yang dirugikan yang melakukan pendaftaran. Pada Universitas Tribhuwana Tunggadewi (UNITRI), informasi dan persyaratan pendaftaran telah dipersepsikan jelas oleh mahasiswa, yang dapat ditemukan melalui brosur yang disebarkan. Jalur dan gelombang pendaftaran Universitas Tribhuwana Tunggadewi (UNITRI) juga telah dipersepsikan beragam, dimana terdapat jalur tanpa tes (hanya seleksi administrasi) di pendaftaran gelombang 1 dan jalur dengan tes di gelombang 2 dan 3. Pada tahun 2019, tes penerimaan pertama diikuti oleh 847 peserta dan kedua 851 peserta Unitri (2018). Dalam gelombang ketiga, tercatat mengikuti tes sebanyak 330 calon mahasiswa baru didominasi dari Sumba, sementara yang lainnya dari Flores dan Kaliman$\tan$ Unitri (2019a).

Dengan melakukan pengujian tren kelompok atas ketidaksamaan dalam penerimaan pendidikan tinggi, penelitian Mok \& Jiang (2016) mengindikasikan bahwa seorang responden dari keluarga yang berpendidikan, lebih sejahtera, dan/atau asal registrasi rumah tangga perkotaan lebih mungkin untuk memasuki pendidikan tinggi. Indikasi ini mendukung adanya hubungan antara sosial ekonomi orangtua terhadap minat anak melanjutkan sekolah yang lebih tinggi Herdiawan (2018). Dalam hasil penelitian Jia and Ericson (2017), terindikasikan bahwa para pelajar dari keluarga dengan latar belakang ekonomi-sosial yang lebih tinggi, sekolah 
menengah atas yang lebih baik dan tempat tinggalnya lebih kekotaan hampir dapat dipastikan terdaftar di sekolah tinggi yang ternama.Hasil penelitian Nurjanah \& Kusmuriyanto (2016) menunjukkan bahwa kondisi sosial ekonomi orang tua berpengaruh 19,8\% terhadap minat melanjutkan ke perguruan tinggi.Universitas Tribhuwana Tunggadewi (UNITRI) hadir bagi semua kalangan masyaraka Unitri (2019b) dimana lulusan SMA/SMK/MA/Sederajat terutama yang ekonominya lemah memiliki peluang yang sama dalam penerimaan mahasiswa.Bahwa kesempatan mendaftar adalah untuk semua golongan, telah dipersepsikan oleh sebagian besar mahasiswa.

Masih ada hal-hal kritis dalam persamaan peluang kesempatan memperoleh pendidikan tinggi pada Universitas Tribhuwana Tunggadewi (UNITRI) seperti promosi kampus dan diskriminasi suku ketika mendaftar. Hal-hal ini perlu mendapatkan perhatian, sebab rerata kedua indikator tersebut berada dalam ukuran ragu-ragu. Apalagi hipotesis penelitian ini diterima sehingga dimungkinkan bahwa masih ada diskriminasi suku ketika calon mahasiswa mendaftar ke Universitas Tribhuwana Tunggadewi (UNITRI). Setiap mahasiswa berhak mempunyai kesempatan untuk masuk ke lembaga pendidikan tinggi apapun tanpa diskriminasi suku maupun golongan karena inilah kriteria dalam persamaan kesempatan. Keseimbangan rasial yang seharusnya menjadi kriteria utama dari kesempatan yang sama adalah tepat dievaluasi kembali secara khusus di dalam konteks perguruan tinggi. Dengan kriteria tersebut, apapun warna kulitnya, mahasiswa dapat menentukan akan kuliah dimana tapi masih sering muncul polemik diskriminasi antara kulit hitam dan kulit putih di dalam kesempatannya mendapatkan pendidikan tinggi. Dalam penelitian Karkouti (2016), disebutkan adanya fakta bahwa mahasiswa-mahasiswa kulit hitam di institusi yang didominasi oleh kulit putih memandang iklim rasial kampus tidak bersahabat, sebagai keterasingan, tidak sensitif secara budaya dan diujikan dampak-dampaknya terhadap pengalaman pendidikan mahasiswa-mahasiswa kulit hitam. Sehingga sebagai sarana meningkatkan iklim kampus seluruhnya, negara seharusnya diijinkan untuk menyediakan kesejahteraan lingkungan pendidikan sedangkan pendidik dan pemangku kebijakan perlu didorong untuk membantu para mahasiswa mengembangkan kesadaran tentang hak istimewa ras.

Mengingat pendidikan tinggi diselenggarakan dengan tanpa membedakan ras, suku, adat istiadat, gender, agama, kedudukan dan status sosial-ekonomi seseorang, maka penerimaan calon mahasiswa harus non-diskriminatif guna memperluas kesempatan. Penelitian ini sebagian besarnya didukung oleh responden yang berasal dari Nusa Tenggara Timur dengan sukusuku, seperti: Ende, Lio, Alor, Timor, dan sebagainya. Universitas Tribhuwana Tunggadewi (UNITRI) memang menerima mahasiswa dari latar belakang suku yang beragam karena menganggap bahwa semua adalah keluarga Unitri (2019a). Mayoritas mahasiswa Universitas Tribhuwana Tunggadewi (UNITRI) berasal dari etnis Flores, Sumba dan lain-lain di wilayah Indonesia Timur. Etnis Flores bangga dengan solidaritas kelompoknya terutama di perantauan, sering mengadakan pesta, merasa satu keluarga karena berasal dari satu kawasan yang sama dan memiliki ciri-ciri fisik dan logat bahasa yang sama Novianti and Tripambudi (2015). Karena kurangnya kesadaran keberagaman golongan, suku dan etnis dari diri sendiri, keluarga, lingkungan, kelompok, bahkan institusi, para etnis asal Indonesia Timur ini rentan merasa terdiskriminasi ketika masuk ke kampus, terutama kampus-kampus yang ada di Pulau Jawa baik negeri maupun swasta, termasuk pula Universitas Tribhuwana Tunggadewi (UNITRI). Berdasarkan hasil penelitian Adelina et al. (2017) di Kota Malang, terdapat prasangka dan intensi melakukan diskriminasi etnis Jawa terhadap mahasiswa yang berasal dari Nusa Tenggara Timur dikarenakan kategorisasi (pembedaan diri, kelompok dan etnisnya dengan orang, kelompok dan etnis lainnya). Hal inipun rawan mengakibatkan terjadinya friksi dan diskriminasi, hingga keinginan untuk mengubah pemikiran buruk masyarakat Jawa tentang masyarakat Indonesia bagian Timur yang dikenal keras, kasar, pembuat onar, dan sebagainya Fitri and Kustanti (2018). Untuk mengurangi prasangka dan diskriminasi yang dapat timbul, diperlukan peningkatkan kontak antar kelompok Kuncoro (2019). Penting pula mengetahui keragaman etnis atau suku dan persamaan kesempatannya sebagai suatu kekuatan. Mahasiswa juga jangan bersikap eksklusif, akan tetapi harus bersikap inklusif dan terbuka terhadap kehidupan yang majemuk, sehingga akan mendekatkan pada situasi yang lebih harmonis daripada situasi yang diskriminatif dan intoleran Khakim et al. (2020). Oleh karena itu, saling bersatu dan 
bekerja sama dengan interaksi yang intens dari berbagai pihak diantara suku-suku di dalam setiap kegiatan kampus sangatlah diperlukan supaya persamaan rasial tercapai.

Hal lain yang perlu menjadi perhatian dari Universitas Tribhuwana Tunggadewi (UNITRI) adalah promosi. Promosi menjadi cara kampus-kampus swasta memperkenalkan diri dan keberadaannya, serta menarik minat para calon mahasiswa. Dengan promosi pula calon-calon mahasiswa akan dapat menangkap peluang, menentukan pilihan dan mengambil keputusan untuk mendaftar ke sebuah kampus swasta. romosi kampus haruslahbersifat ajakan, relevan dan dapat diterima oleh semua etnis dan golongan agar dapat menjadi pertimbangan calon mahasiswa dalam menentukan kampus pilihan. Dijelaskan dalam temuan-temuan Suliyanthini (2015) bahwa pertama, program promosi kampus mempengaruhi pandangan pelamar tentang kampus. Kedua, program promosi kampus mempengaruhi keputusan pelamar di dalam kelanjutan studinya pada sebuah kampus. Pada umumnya, pandangan yang bagus berasal dari komunikasi promosi. Berikutnya berdasarkan penelitian Pamungkas (2015), sumber informasi yang diperoleh calon mahasiswa menjadi faktor utama lanjutnya proses pendaftaran hingga sampai menjadi mahasiswa, seperti: internet, orang tua, teman, testimoni kakak kandung (saudara dekat/jauh) dan tetangga yang pernah atau sedang kuliah di sebuah kampus. Untuk promosi, pihak BSI menyediakan penawaran biaya kuliah D3 (Diploma) atau S1 (Sarjana) dengan harga terjangkau, dapat dicicil namun fasilitas kelas dan teknologi kampus tetap terjaga (Meliala, 2018). Pada Institut Sains dan Teknologi Al-Kamal (ISTA), dilakukan promosi berdasarkan potensi akademik mahasiswa dengan strategi promotion mix Kurniawati et al. (2017).UPMBtelah memiliki program "Safari" yang dapat mempromosikan UNITRI dan mengenalkan kepada SMA/SMK dan PGRI (Unitri, 2018). Perlu juga program ini menyasar daerah atau sekolah potensial yang belum dikunjungi sebelumnya di Malang Raya dan wilayah lainnya.

\section{KESIMPULAN}

Persamaan kesempatan terbagi ke dalam kesempatan peluang dan aturan. Persepsi terhadap persamaan kesempatan memperoleh pendidikan tinggi pada Universitas Tribhuwana Tunggadewi (UNITRI) adalah benar reratanya secara signifikan sama dengan 6 dalam persepsi mahasiswa S1. Dari kesempatan aturan, sebagian besar mahasiswa S1 angkatan 2019 Universitas Tribhuwana Tunggadewi (UNITRI) mempersepsikan "ya", sedangkan untuk peluang masih diragukan. Kesempatan peluang yang masih diragukan adalah promosi dan diskriminasi sehingga sebaiknya pola promosi dan komunikasi kampus Universitas Tribhuwana Tunggadewi (UNITRI) selama ini dievaluasi dan disusun strategi baru. Perlu dilakukannya studi lanjut mengenai kedua hal ini dan aspek lain dalam kaitannya dengan penerimaan mahasiswa Universitas Tribhuwana Tunggadewi (UNITRI) agar berkeadilan.

\section{UCAPAN TERIMA KASIH}

Penelitian dan publikasi jurnal ini telah didukung dengan pendanaan dari Program Hibah Penelitian Dosen UNITRI Tahun Anggaran 2019/2020 Nomor: 05/TB-LPPM/TU-220/I/2020. Untuk itu, disampaikan terima kasih kepada Universitas Tribhuwana Tunggadewi (UNITRI) Malang.

\section{REFERENCES}

Adelina, F., Hanurawan, F., and Suhanti, I. Y. (2017) Hubungan antara prasangka sosial dan intensi melakukan diskriminasi mahasiswa etnis Jawa terhadap mahasiswa yang berasal dari Nusa Tenggara Timur. Jurnal Sains Psikologi 6, 1-8. doi: http://dx.doi.org//10.17997/ um023v6i12017p001.

Alfian and Diskominfo (2019). Pemerintah Kabupaten Sanggau Mendapat Kunjungan Dari Unitri Malang. https://diskominfo.sanggau.go.id/baca/02-12-2019/ pemerintah-kabupaten-sanggau-mendapat-kunjungan- dari-unitri-malang/. (Accessed on 2020-01-15).

Fitri, R. and Kustanti, E. R. (2018). Hubungan antara efikasi diri akademik dengan penyesuaian diri akademik pada mahasiswa rantau dari Indonesia bagian timur di Semarang. Jurnal Empati 7, 66-77.

Gustian, D. (2016). Persepsi Masyarakat terhadap Pendidikan Perguruan Tinggi (Studi Deskriptif tentang Kurangnya Minat Pendidikan Ke Jenjang Perguruan Tinggi pada Pemuda dan Pemudi Kampung Pungkur Loji Desa Cicalengka Kulon Kecamatan Cicalengka Kabupaten Bandung) . http://digilib.uinsgd.ac.id/id/eprint/3862.

Herdiawan, T. A. (2018). PENGARUH SOSIAL 
EKONOMI ORANG TUA TERHADAP MINAT ANAK MELANJUTKAN SEKOLAH KE JENJANG YANG LEBIH TINGGI (Studi Deskriptif di Desa Buniara Kecamatan Tanjungsiang Kabupaten Subang). http://repository.unpas.ac.id/id/eprint/37483.

Jia, Q. and Ericson, D. P. (2017). Equity and access to higher education in China: Lessons from Hunan province for university admissions policy. International Journal of Educational Development 52, 97-110. doi: 10.1016/j.ijedudev. 2016.10.011.

Karkouti, I. M. (2016). Black students' educational experiences in predominantly white universities: A review of the related literature. College Student Journal 50, 59-70.

Khakim, M. S., Nugraha, A. F., Sukanti, S., and Sarwedi, A. R. (2020). KONTRIBUSI MAHASISWA DAERAH DALAM PENANGANAN INTOLERANSI MELALUI SINERGI PERGURUAN TINGGI DI DIY. Jurnal Pendidikan Kewarganegaraan 10, 62-62. doi: 10.20527/ kewarganegaraan.v10i1.8361.

Kuncoro, B. S. (2019). Faktor - Faktor Yang Mempengaruhi Pengambilan Keputusan Menjadi Tenaga Kerja Indonesia. EFFICIENT Indonesian Journal of Development Economics 2, 326-335. doi: 10.15294/efficient.v2i1.28402.

Kurniawati, I., Indrajit, R. E., and Fauzi, M. (2017). Peran Bussines Intelligence Dalam Menentukan Strategi Promosi Penerimaan Mahasiswa Baru. IKRA-ITH INFORMATIKA. Jurnal Komputer dan Informatika 1, 70-79.

Lazenby, H. (2016). What is equality of opportunity in education? Theory and Research in Education 14, 65-76. doi: $10.1177 / 1477878515619788$

Mitasari, Z. and Istikomayanti, Y. (2017). STUDI POLA PENYESUAIAN DIRI MAHASISWA LUAR JAWA DI UNIVERSITAS TRIBHUWANA TUNGGADEWI MALANG. In SENASPRO 2017 | Seminar Nasional dan Gelar Produk, Malang, ed. and others (SENASPRO 2017 | Seminar Nasional dan Gelar Produk), 796-803.

Novianti, D. and Tripambudi, S. (2015). Studi fenomenologi: Tumbuhnya prasangka etnis di Yogyakarta. Jurnal Ilmu Komunikasi 12, 119-135.

Pamungkas, P. D. A. (2015). Menentukan Kemungkinan Masuknya Calon Mahasiswa Baru Pada Sebuah Perguruan Tinggi Swasta Manggunakan Teknik Klasifikasi Pohon Keputusan Dengan Aplikasi Rapidminer 5. Jurnal Informatika 1, 45-50.

Salehi-Isfahani, D., Hassine, N. B., and Assaad, R. (2014) Equality of opportunity in educational achievement in the Middle East and North Africa. The Journal of Economic Inequality 12, 489-515. doi: 10.1007/s10888-013-9263-6.
Suliyanthini, D. (2015). Effect of Campus Promotion, Service Quality and Applicants' Image toward Their Decision in Choosing a Higher Education Institution. American Journal of Educational Research 3, 208-210.

Turner, R., Shulruf, B., Li, M., and Yuan, J. (2012). University admission models that address quality and equity. Asia Pacific Journal of Education 32, 225-239. doi: 10.1080/ 02188791.2012 .684955$.

Unitri, H. (2018). Tim Safari UPMB UNITRI Adakan Rapat Koordinasi. https://unitri.ac.id/tim-safari-upmb-unitri2018-adakan-rapat-koordinasi/. (Accessed on 2020-0110).

Unitri, H. (2019a). Pesan Rektor UNITRI dan Bupati Sanggau Dalam Pembukaan ORDIK 2019/2020. https://unitri.ac.id/pesan-rektor-unitri-dan-bupatisanggau-dalam-pembukaan-ordik-2019-2020/. (Accessed on 2020-01-16).

Unitri, H. (2019b). UPT PMB UNITRI GELAR TEST PEMABA GELOMBANG 3 TH AJARAN 2019/2020. UPT PMB UNITRI Gelar Test Pemaba Gelombang 3 Th Ajaran. https://unitri.ac.id/upt-pmb-unitri-gelar-testpemaba-gelombang-3-th-ajaran-2019-2020/. (Accessed on 2020-01-17).

Wea, A. G. and Adiwidjaja, I. (2018). Pengaruh Beasiswa Terhadap Motivasi dan Prestasi Belajar Mahasiswa Universitas Tribhuwana Tunggadewi Malang. JURNAL ILMU SOSIAL DAN ILMU POLITIK 7, 21-25.

WEST, A. and NIKOLAI, R. (2013). Welfare Regimes and Education Regimes: Equality of Opportunity and Expenditure in the EU (and US). Journal of Social Policy 42, 469493. doi: $10.1017 / \mathrm{s} 0047279412001043$

Conflict of Interest Statement: The authors declare that the research was conducted in the absence of any commercial or financial relationships that could be construed as a potential conflict of interest.

Copyright (๑) 2020 Fithriana and Firdausi. This is an openaccess article distributed under the terms of the Creative Commons Attribution License (CC BY). The use, distribution or reproduction in other forums is permitted, provided the original author(s) and the copyright owner(s) are credited and that the original publication in this journal is cited, in accordance with accepted academic practice. No use, distribution or reproduction is permitted which does not comply with these terms. 


\section{LIST OF TABLES}

1 Rekapitulasi Jawaban Variabel Persamaan Kesempatan . . . . . . . . . . . 196

2 Hasil Uji Z Pada Persepsi Mahasiswa . . . . . . . . . . . . . . . . . . . . . 197 
TABLE 1 | Rekapitulasi Jawaban Variabel Persamaan Kesempatan

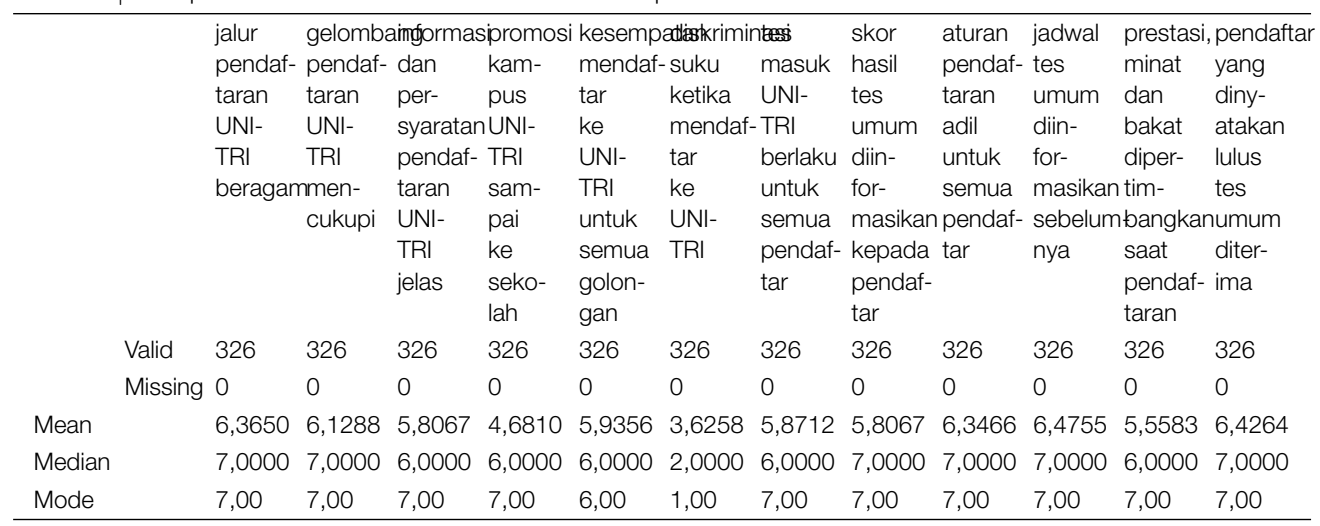


TABLE 2 | Hasil Uji Z Pada Persepsi Mahasiswa

z_statistic p_value cohens_d

,00000 1,00000,00000

$000001,00000,00000$

,00000 1,00000,00000

$-9,02774,00000-, 50000$

,00000 1,00000, 00000

$-18,0555,00000-1,00000$

,00000 1,00000,00000

00000 1,00000,00000

,00000 1,00000,00000

,00000 1,00000,00000

,00000 1,00000,00000

00000 1,00000, 00000

Number of cases read: 12 Number of cases listed: 12

Sumber: Data Primer Diolah, 2020 